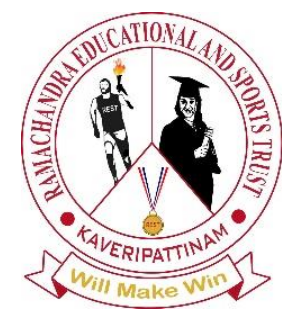

REST Journal on Emerging trends in Modelling and Manufacturing

Vol: 6(4), 2020

REST Publisher

ISSN: 2455-4537

Website: www.restpublisher.com/journals/jemm

\title{
An Impact of Agricultural App's in Selling the Crops by Farmers
}

Parimala. S, Sushma. M,

Acharya Institute of Graduate Studies, Bengaluru, India,

parimalas@acharya.ac.in, sushmam@acharya.ac.in

\begin{abstract}
If agricultural goes wrong, nothing else will have a chance to go right in the country, common man spends major of his income to the food consumption but on other side the farmers not able to get proper return on investment they have so many hurdles starting from selection of crop, fertilizers, pesticides, irrigation,power supply along with this after harvesting they are not able to sell their crops on market price, to overcome this Government and other app developer developed the APPs specially for farmers ,this study tries to bring out the real impact of that agricultural app on the farmers in marketing the crops, so to analyse this we have interviewed more than 10 farmers in states like Karnataka, Bihar, Maharashtra, Kerala, Tamil nadu, we have used Snow ball sampling method and we have found out some interesting facts \& we have suggested few points to policy makers or App developer. Key Words: Agri APP, Fertilizers, Pesticides, App developer.
\end{abstract}

\section{Introduction}

Agriculture is the primary sector of Indian economy, in India currently we can find 150 Million farmers are directly involved in cultivation, which includes both Production and livestock. If agriculture contributed a lot is to the rise of civilization.

Agricultural App

The Word Agriculture is derived from Latin Word 'Agri' which means Field, cultivation. Agricultural App it is a mobile app which can be used by the farmers.
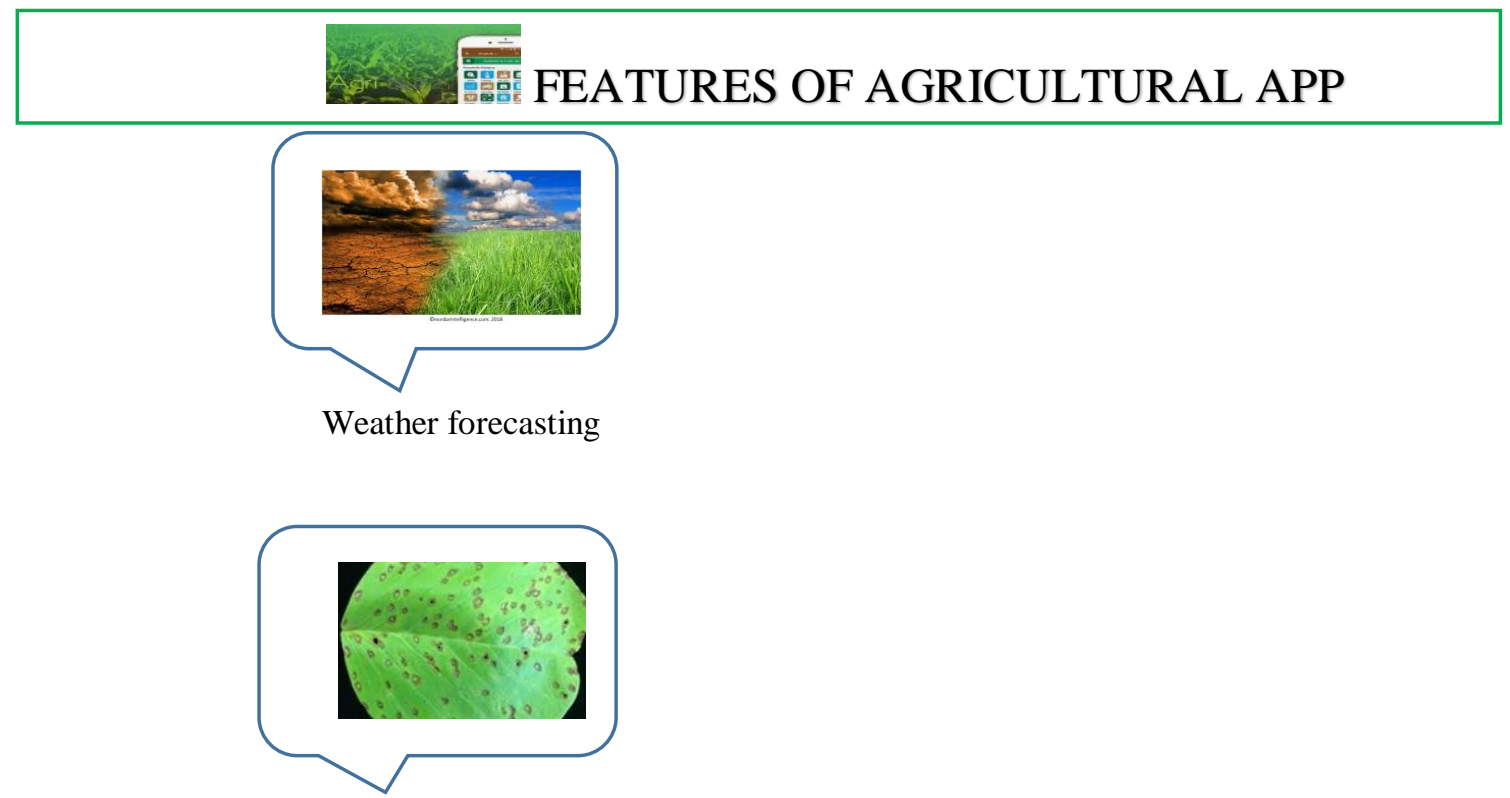

Diagnosis of disease crop schedules \& their treatment

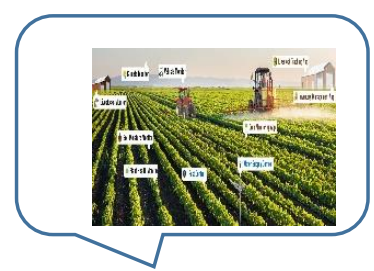

Uses GPS tracking of $50 \mathrm{KM}$ to get good market price for the crops 


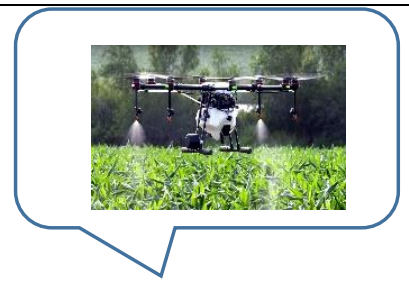

Utilizing drones with app

Angaru E extension was the first Mobile Agri app developed by Acharya N G Ranga Agricultural University scientists P.B. Pradeep and team, the main features of this app farmers can text, and send audio or video related to cultivation and provided toll free number to contact the University for any Technical Assistance. Currently we can find so many Agricultural E -Apps which is started to help the farmers on other side the Government provided the App to farmers namely Kisan Suvidha, Pusa krishi, M Kisan Application, Crop insurance Android App, Farm-o-Pedia App, Shetkari Masik Android App, Agri market app.

\section{TOP 10 AGRI APP AS ON 2019.}

1. ABRIDGE App

2. RRXtend spray app

3. Xarvio scouting app

4. Cropstream app

5. Field Check app

6. Arisync app

7. Kugler timing app

8. Agsense app

9. FieldAgent app

10. Agellus app

\section{Objectives}

1.To know how many farmers are using Agricultural app.

2.To study how the agricultural app are helping them on marketing their crops.

3.To suggest the special features to be in upcoming Agricultural app.

\section{Review of Literature}

"Anytime, anyplace, anywhere"-A sample selection model of mobile internet adoption in German agriculture, Marius Michels Wilm Fecke Jan-Henning Feil Oliver Musshoff Frederike Lülfs-Baden Saskia Krone,(2020), this study tells about how mobile internet can be adopt in agriculture, to analysis this they have selected 815 German farmers as a representative data and they used bivariate model, this study stated the age of the farmer, farm size, and location as well as internet risk which is associated with adoption of mobile internet in agriculture along with this they found out that the few farmers are not ready to get digitalized and they have not facilitated with good mobile internet infrastructure. A Study on the Application Model of B2B E-Commerce in the Agricultural Sector, Zhang Jin-long, Du Xiao-fang,2004, they studied about application of Main E- commerce model one is e-commerce intermediation model (EMIM) and one more Integrative content centre model(ICCM),they have concluded that the ICCM will be transition from local e-commerce and integrative e-commerce ,they have informed that E-commerce will follow the direction of integrative e commerce for development of e commerce, while ICCM will be transition from local e commerce to integrative e-commerce which is based on supply chain model on the e hubs to develop the e commerce.

\section{Research Methodology}

This study depends on primary data collected through interviewing via phone to more than 10 farmers from Bihar, Karnataka, Maharashtra, Tamil nadu, and Kerala. For this study we have used out the snowball sampling method. This study primarily covers rural and urban. 


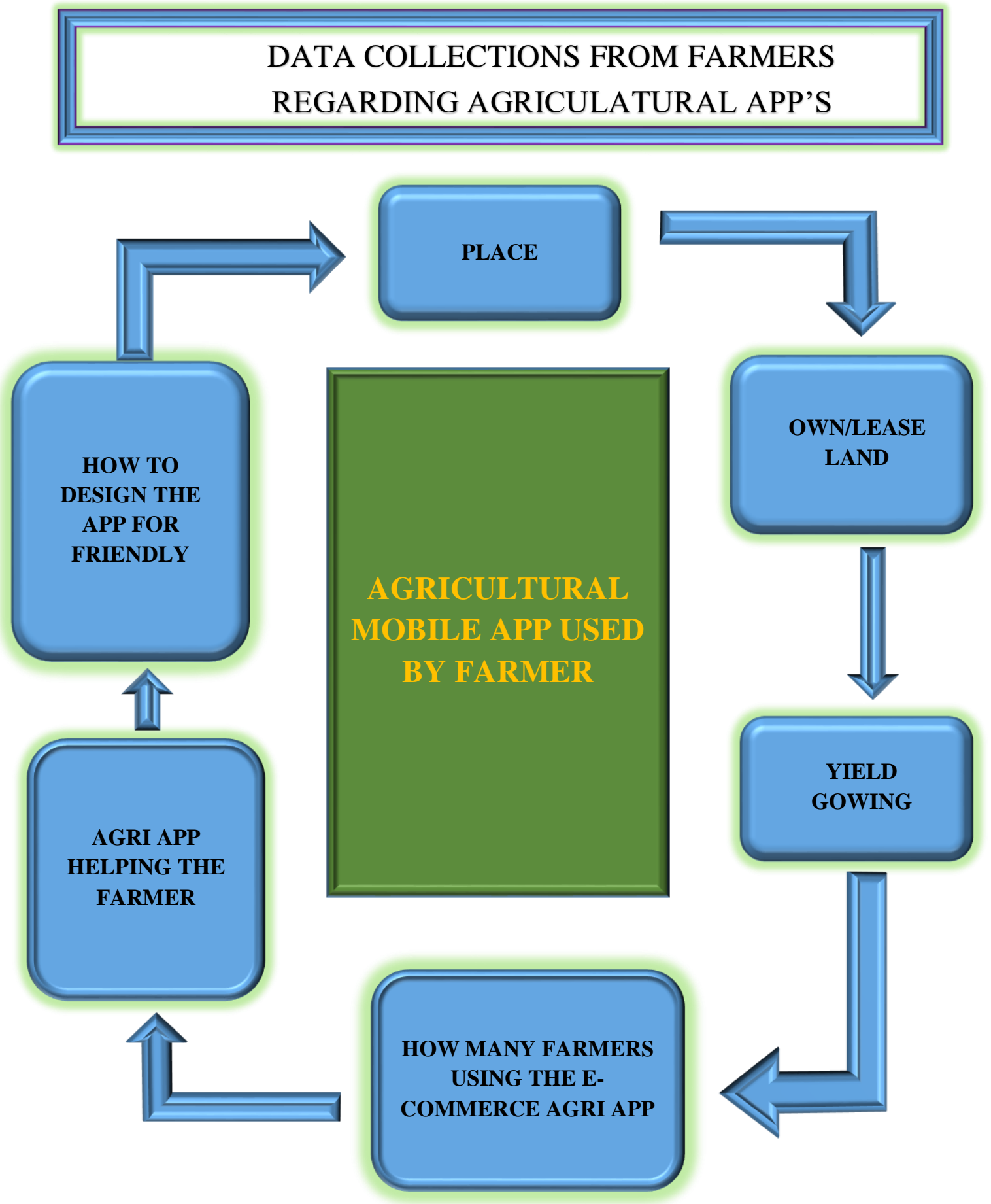

Fig. 1: Showing the steps of data collections from farmers

A.Place: This study covers Bihar, Tamil nadu, Karnataka, Maharashtra and Kerala.

B.Own or lease land: All the farmers are having own land, average one farmer's have10-12-acre land. In seasonal time they will take 20-25 labor for work if not the family members will be taking care of work in land.

C.Yield growing: The major yields like rice, arecanut, ragi, chilly, silk, coconut, sugar cane, maize, cotton, pepper, etc.,

D.How many farmers are using $\mathbf{E}$ commerce Agri App: we have contacted more than 10 farmers, in that the farmer from the Bihar who is owing more than 10 acre of land growing rice, wheat, in seasonal time they will be calling 30-40 labor After harvesting they usually sell directly to Jharkhand and Kolkata as ₹10,000 or ₹18000 per quintal and they are selling to consumer to 20000 per quintal, so here when we asked about the Agri app they informed that they were not aware of any such apps. In Bengaluru we have interviewed one farmers who have 22 acre of own land in seasonal time they will call 2030 labors, they are growing the Ragi, arecanut and after the harvesting they have sale to local market with normal price, when we have asked about the Agri app they were not have any idea about. Next we have contacted they have Ramanadhapuram district who is having 15 acre of own land and there yields are rice and silk worm and they have 25 un skilled labor after harvesting they are selling to Kerala and other vendors as $1 \mathrm{~kg}$ for 55 rupees and here for this farmer they know about the 
Agri APP they have used but in that App (Ulagham APP) they got some information like the availability of fertilizers nearby there job but when they went it was not available)like this they got wrong information for 2-3 times due to this they lost the hope on that App \& they are stopped using this app. And few more farmers from Madurai and other parts of Tamil nadu who have own land of 4-5 acres their main yield chilly, rice, silk worm, coconut they have labor around 20-30 unskilled labor after the harvesting they have sold to local commission market and they were having awareness about the app but they were not knowing how to use it. Again we have contacted the farmers from Belgaum who have 0.5 acre own land who is growing paddy, sugar cane, the family members are working after harvesting they are selling to local market for 1 tone is 3000 then here they are skilled farmer but they don't know about the Agri App and one more 8 acre who is growing maize ,cotton they are selling to very selling price in next local market more over in entire Belgaum the $80 \%$ farmers don't know about the Any app which is related to agricultural marketing. Then when we have spoken with Farmer from Kerala who is having 12 Acre own land who has yielded coconut, arecanut ,pepper, paddy, they have around 3-4 labor after harvesting they are selling to local market and export to Nagpur they don't have any knowledge about Agri app but they have Local what's app group were they are more than 1000 farmers they are getting information about the demand about their product and along with this they are Started under NABARD the Mahatma Farmers club were in this are helping the farmers giving Fruits seeds and were they can get a training also. In Maharashtra we have found the farmers who are having 3-4 acres for each farmers who is growing rice, ground nuts, sugarcane, soya bean, and tobacco here after harvesting they use to sell in there nearby local area and all the farmers are un skilled they don't have knowledge about the Agri app. And we have taken Tumkur then have 2-3 acre they grow Coconut and they will sell in local market they are they know about the Agri app but they are not using because they expecting to sell in large quantity.

E.Agri App is helping the farmer: In our overall studies only 2-3 farmers are using that to they are telling whatever they are informing in the app that information if not valid so the app should be updated by the app developer offenly.as most of them are not mobile friendly they don't know what is this all about.

F.How to design the app for friendly: The farmers are Asking that the app should be in their regional language and they have to tell currently where is the demand for the product and for what best price they can sell the products, in some place there is a more demand for harvesting machine so this app have to inform them nearby any harvesting machine is available are not and regularly they need to update about the demand of their product and more over this app should be very simple and friendly.

\section{Finding}

We have started the research to know the impact of E commerce Agri apps for farmers to sell their crops for good market price for this study we have selected Snow ball sampling. Study reveals that the farmers are having own land but most of the farmers they don't know the about any agricultural app Through this analysis we came to know that all the farmers have their own land in acres but $98 \%$ of farmers they don't have knowledge regarding the E-commerce Agricultural Apps only $2 \%$ of responded using the APP but they are not satisfied with their service because A farmer from Ramanadhapuram there was Uzlavan app he need fertilizer when he searched the app was showing that the fertilizer is one local shop in market but when he visited that shop they replied they fertilizers are not available like this it as happened twice to him so due to this he stopped this app is providing wrong information due to this he stopped using this app and more over they are still following the barter system like they are taking 10 bags of fertilizers and after harvesting they are giving 10 barges of crop to the fertilizers shop so due to this they are selling to outsiders or exploring much. Along with this they have issues like water, weather conditions.

\section{Suggestion}

The App developer and government are developing many apps to support the farmers but the one main thing they need to bring awareness about this because many farmers they don't have awareness about this and they don't know how to use, so in all gram panchayth level first they need to create the awareness about the Best apps which will help the farmers and along with that they need to train them regularly, for this any organization or university or NGO can voluntarily train the farmers in this in other side the app developer have to update the app regularly and Farmer association have to support the farmers to get a $0 \%$ Interest loan and they have bring the awareness about crop insurance because if they lost in natural calamities they can easily claim the amount, then we need to encourage the upcoming generation to the Agricultural Field then automatically the Digitalization can be come in Agri Field also.

\section{Conclusion}

Every person in this universe are very busy in full filling wants like, money, cloth, shelter, food. As per some studies states that average $50 \%$ income we will spend on food but that is not reaching farmer because of the intermediaries to overcome this the App has been for farmers but still they are getting good rate return because due to lack of awareness \& illiteracy when educated peoples are getting into the fields of cultivation then we can bring lot of changes in agriculture.

\section{Reference}

[1].Jin-long, Z., \& Xiao-fang, D. (2004). A Study on the Application Model of B2B E-Commerce in the Agricultural Sector. [2].https://onlinelibrary.wiley.com/doi/full/10.1002/agr.21635

[3].https://www.ceeol.com/search/article-detail?id=856702

[4].https://link.springer.com/chapter/10.1007/978-981-13-9640-3_14

[5].https://link.springer.com/chapter/10.1007/978-3-030-40749-0_16 
[6].https://www.sciencedirect.com/science/article/pii/S1877343519300612

[7].https://aec.afdb.org/sites/default/files/papers/232-fiamohe_rose-

modernizing_postharvest_operations_services to attract_youth_in_agribusiness.pdf

[8].http://www.pertanika.upm.edu.my/Pertanika\%20PAPERS/JSSH\%20Vol.\%2027\%20(3)\%20Sep.\%202019/16\%20JSSH -2524-2017.pdf

[9].https://www.emerald.com/insight/content/doi/10.1108/BFJ-06-2018-

0403/full/html?casa_token=f0xAeSem1_cAAAAA:dAJ0_CJSayp0kBd4ADLChdtpeWZ6Qlb0syRLZK42eC3t5TOalpgL2f ypWzIrdvsVvkCW6uI4VqBrphqg9oV0SB4IcD4rbTo992BQxajmCPbnFiwNLDAeOA 